Methods Patients at Shanghai Ruijin Hospital from 2014 to 2016 were consecutively enrolled. They were divided into UGI+ group and UGI- group based on endoscopy and pathology results. Features of UGI-CD were analyzed and the prognosis was followed-up.

\begin{tabular}{llllll}
\multicolumn{6}{l}{ Abstract IDDF2019-ABS-0154 Table 1} \\
\hline & Ulcer & $\begin{array}{l}\text { Protruding } \\
\text { lesions }\end{array}$ & $\begin{array}{l}\text { Bamboo joint-like } \\
\text { appearance }\end{array}$ & Stenosis & Fistula \\
\hline $\begin{array}{l}\text { Esophagus } \\
\text { Gastric fundus }\end{array}$ & 4 & & $14(20.6 \%)$ & 1 \\
Gastric body & 1 & 1 & & & \\
$\begin{array}{l}\text { Stomach Angle } \\
\text { Gastric antrum }\end{array}$ & 1 & 6 & & 2 & 1 \\
$\begin{array}{l}\text { Pylorus } \\
\text { Duodenal bulb }\end{array}$ & 12 & $10(14.7 \%)$ & & \\
$\begin{array}{l}\text { Duodenal } \\
\text { descendent }\end{array}$ & 4 & & & & \\
Total & 31 & $17(25 \%)$ & $14(20.6 \%)$ & $4(5.8 \%)$ & $2(2.9 \%)$ \\
& $(45.6 \%)$ & & & & \\
\hline
\end{tabular}

Results 76 subjects were enrolled in this study. (1) 46 cases $(60.5 \%)$ had 68 positive endoscopic manifestations. Endoscopic features were diverse and the bamboo joint-like appearance of the gastric fundus had the highest incidence, followed by duodenal ulcers and bamboo joint-like appearance of the duodenal bulb (table 1 and figure 1). According to the UGI-SESCD, patients with a score of 5 and above accounted for only $23.9 \%$.

(2) Male sex and presence of ileocolon lesions were independent risk factors for UGI-CD $(\mathrm{p}<0.05)$.

(3) No significant difference between the UGI+ group and the UGI- group in the 3-year no surgery and the 3-year no complication rates $(\mathrm{p}>0.05)$. Further subgroup analysis showed that the 3-year event-free survival rate in the UGI+DB+ group $(68.0 \%)$ was significantly lower than that in the UGI$(88.9 \%)$ and UGI+DB- (87.9\%)groups ( $p=0.015)$.

Conclusions Upper gastrointestinal tract involvement in newly diagnosed CD patients is not rare. UGI+ patients with duodenal bulb involvement had significantly higher rates of surgery or complications. Therefore, active treatment should be promptly provided to this subgroup of patients to improve their prognosis.

\section{IDDF2019-ABS-0155 THE CLINICAL FEATURES AND PROGNOSTIC FACTORS OF PRIMARY GASTROINTESTINAL DIFFUSE LARGE B- CELL LYMPHOMA: A SINGLE CENTER STUDY OF 312 PATIENTS}

Yubei Gu*, Qiangqiang Wu, Pengpeng Xu, Jie Zhong. Rui Jin Hospital, Affiliated to Shanghai Jiao Tong University, School of Medicine, China

\subsection{6/gutjnl-2019-IDDFabstracts.170}

Background To investigate the clinical features and prognostic factors of patients with primary gastrointestinal diffuse large B-cell lymphoma (PGI-DLBCL).

Methods De novo PGI-DLBCL patients treated in Shanghai Ruijin hospital from January 2000 to January 2017 were enrolled. Clinical data, endoscopic profiles, imaging, pathological features were retrospectively analyzed.

Results 312 PGI-DLBCL patients were included. The median age of onset was 59 years. (1)Clinical manifestations: abdominal pain $(58.7 \%)$ and B symptoms (34.3\%) were the most common clinical manifestations. Other manifestations included gastrointestinal bleeding, intestinal obstruction, abdominal mass and perforation. (2)The involved areas: The most involved areas were the stomach, 58.3\%, colon, $28.2 \%$, duodenal and small intestine, $20.2 \%$ and esophagus (0.6\%), among which 23 cases $(7.4 \%)$ presented multiple

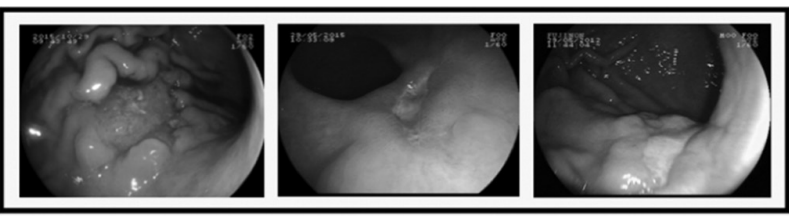

Ulcer type

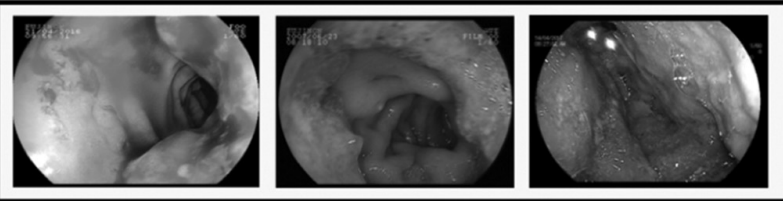

Diffuse infiltration

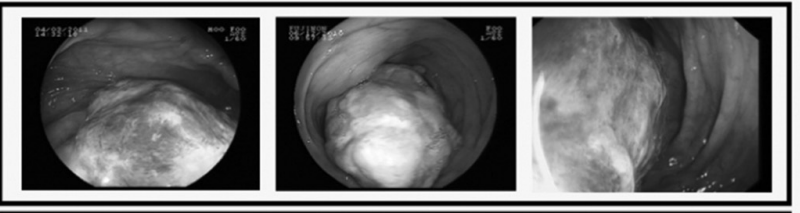

Protruded lesion

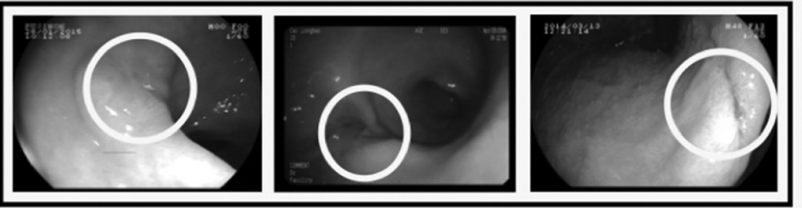

Superficial type

Abstract IDDF2019-ABS-0155 Figure1 Endoscopic features of PGI-DLBCL 